\title{
Concept, conception and misconception of old people's homes in Nigeria
}

\begin{abstract}
The choice of old people's home is due to the falling traditional family system as children are in search for greener pasture. Hence, the concept of old people's homes has been viewed as an abuse of institutionalizing the older population. The paper is a review of the concept of old peoples homes, conception of old peoples homes around the world and Nigeria in particular and also the misconception attached to old peoples homes in Nigeria. The paper $\mathrm{x}$-rayed the emerging roles of social workers in providing long term care. The paper recommended that old peoples home should not be seen as an elder abuse but as an alternative to provide long term care for the elderly in a gradually falling African family traditional system.
\end{abstract}

Volume 2 Issue 6 - 2017

\author{
Oyinlola Oluwagbemiga,' Oyinlola \\ Oluwayinka Tiwalade ${ }^{2}$ \\ 'Senior Medical Social Worker and Medical Social Services \\ Department, University College Hospital, Nigeria \\ ${ }^{2}$ College of Health Sciences, Ladoke Akintola University of \\ Technology, Nigeria
}

\author{
Correspondence: Oyinlola Oluwagbemiga, Senior Medical \\ Social Worker and Medical Social Services Department, \\ University College Hospital, Nigeria, \\ Email oluwagbemiga.oyinlola@yahoo.com
}

Received: September 23, 2017 | Published: December 19 2017

\section{Introduction}

From time in memorial old peoples home is not a common style and maybe not in existence, but to the failing traditional family system of care for the elderly lead to the emergence of old people's home. The concept of old peoples home has been regarded as western ideology to an institutionalized centre to care for the elderly while the children are busy navigating the socioeconomic odds of life.

In African, old people are living in long-term care as the fastest rate, it becomes very important this population would need day-to-day help with activities such as washing and dressing or help with household activities such as cleaning and cooking, reminding them about drugs and medical care. This type of support (along with some types of medical care) is what is in trend now is the long-term care. However, the $\mathrm{WHO}^{1}$ envisaged that, the demand for long-term care is expected to rise within the African region, thanks in part to ageing populations and increasing prevalence of long-term conditions such as dementia. Hence, the problem with the availability and affordability of longterm care services varies dramatically between African countries.

Inspite of increasing ageing society with the region there are a lot challenges facing old peoples home care services in Nigeria and sub-saharan African region with rates of functional impairment in Nigerian older populations which are on a par with, or even exceed those in other parts of the globe, suggesting an already significant need for old peoples homes within the region. ${ }^{1}$ This article x-rayed the concept, conception and misconception of old people's homes in Nigeria.

\section{Concept of old people's homes}

Old people's home or long term care facility for old people is a multi-residence housing facility intended for senior citizens ages $60 y e a r s$ and above. This could also be referred to as retirement home or could be called nursing home. A typically, physical structure allows person or couple in the home has an apartment-style room or suite of rooms. The old people's homes is always a well structure set- up to provide formal long term care for older peoples with either impairment with daily functioning or whose children are busy with the socioeconomic odds of life coupled with family stressors and could not meet up with the demand of care of their parents. ${ }^{2}$ Old people's homes meets a variety of services which help meet both the medical and non-medical needs of people with a chronic illness or disability who cannot care for themselves for long periods. ${ }^{3}$

Key facilities required of an old people's homes include facilities for meals, gatherings, recreation activities, transport services, ambulance services, some form of hospice care, well-furnished insuite rooms, movie rooms etc. A place required for a long term care should be located in sub-hub community and not close to the main road to avoid accident. The home could be paid for on rented apartment, or can be bought in perpetuity on the same basis as a condominium. However, the difference between old people's home and nursing home is primarily in the level of medical care given. It is important to understand the dynamics of this population as many elderly persons seem to die gradually having no place to go, no sight to see, no exercise for mind or body hence the need for long term care services.

\section{Conception of old people's homes}

In the twenty-first century, old people's homes have become a standard form of care for the most aged in Nigeria and sub-Saharan African region. Nearly 6 percent of older adults are sheltered in residential facilities that provide a wide range of care. Yet such institutions have not always existed; rather, their history and development reflect relatively recent demographic and political realities that shape the experience of growing old. ${ }^{4}$ Before the nineteenth century, no age-restricted institutions existed for longterm care. Rather, elderly individuals who needed shelter because of incapacity, impoverishment or family isolation often ended their days in an almshouse. Placed alongside the insane, the inebriated, or the homeless, they were simply categorized as part of the community's most needy recipients. 
In the beginning of the nineteenth century, women's and church groups began to establish special homes for the elderly persons. Often concerned that worthy individuals of their own ethnic or religious background might end their days alongside the most despised society, they established as the founder of Boston's Home for Aged Women (1850) explained a haven for those who were "bone of our bone, and flesh of our flesh". Advocates for these asylums contrasted their benevolent care with the horrors of those who were relegated to the almshouse. Although the homes were designed for those without substantial familial support these early old people's homes still generally required substantial entrance fees and certificates of good character. Through these policies, the founders strove to separate their own needy poor from, as the Boston founder explained, foreigners who "have taken possession of the public charities. Not surprisingly, perhaps, throughout the nineteenth century the numbers of elderly people who found shelter in these institutions was rather limited (FATE, 2014).

It is often claimed that the African cultures make adequate provisions for the care of the elderly. However, observations and happenings have shown that it is not always true. The dispersal of children relations in search of social and economic opportunities and in many cases loss of spouse, death of friends and psycho-social disengagement of life leave the elderly isolated and lonely, underfed, gaunt face, poorly clad and struggling with life. Many are just living fossils. These factors aggravated by the inevitable progress of old age which shows down the individuals, go to emphasize the need for homes and attention for neglected elderly, and such as could be provided in a home for the aged. ${ }^{5}$ Old people in Nigeria generally live in and receive care in their own home or residence of children or relations. This, however, is not saying that the care is satisfying or that there are no cases of neglect of the aged. Government policy would want the use of old people's home de-emphasised while communitybased support system should be encouraged both are necessary in these circumstances.

According to Okunola ${ }^{5}$ Old people's home started with institutions for the care of aged persons in Ibadan, they operated under the auspices of the missionary group. the inmates were mostly females and most of them, by and large senile had been collected, which indicated they are from the way, rescued from unruly crowds who yelled at them, giving the impression that, they were being rewarded for alleged sins of the past, the sins of being 'witches and wizards. From the report of Okunola ${ }^{5}$ that, old people's homes is best promoted at the local level with local communities participating in its management, but pilot projects could be promoted at State and national for the purpose of demonstrating standards.

Unfortunately, there is no existing data on old people's home in Nigeria as the only existing ones are registered with either Ministry of Health or Ministry of Social Welfare but without a National data base. However, the list of long term care facilities or old people's home known include: Old people's home Mushin, Lagos, operating for Regina Mundi Catholic Church, Mushin, Old people's Home, Yaba, Lagos; Help Old people, Africa (HOPA), Kaduna, Old people's home, Asaba, Delta State, Old people's home, Warri, Delta State, Old women's homes mercy convent, Benin, Edo State, Little sisters of the poor, Enugu State, Old people's home, Shanuchi, Kano State, Ile Alafia Roman Catholic Relief Centre, Apata, Ibadan, Home for the elderly, Port-Harcourt, River State, Roccetti Care Home for Old people, Moniya, Ibadan, Senior Citizens Palace, Ibadan, Geriatric
Centre, owned by University College Hospital, Ibadan all in Nigeria and Emmanuel Alayande Senior Citizens Home (Oyinlola 2015). Although most of the old people's homes are not registered with relevant regulatory agencies like Ministry of Health and Ministry of Social Welfare.

\section{Misconceptions about old people's home in nigeria}

The concept of old people's home is not traditionally an African concept, rather a concept in the Western culture. Except for the fact that, cross cultural adaptation are features in modernization, the traditional African and Nigerian way of managing older persons was rooted in the extended family base. In it everyone belongs; parent, grandparents, uncles, aunts, brothers, sisters, cousins, nephews, nieces, adult children's spouses, and so on. Care of older persons is undertaken by these members of the extended family. ${ }^{6}$ Such caregiving responsibilities include, but not limited to, cooking meals and feeding, laundry, medical sustenance, provision of basic amenities transportation, providing financial and housing support.

Ajomale $^{7}$ however pointed out that added to all this the decline in the economy, gradual disintegration of the extended family system, unemployment, increasing female employment to complement family income, as well as rural-urban migration all contributing to the noticeable decline level of care giving offered older persons. Also the quick fix procedures in the family, work and society, characteristic of the computer technology age, compels a virtually 'hurried-up' lifestyle, which also adversely affect quality of care giving to older persons. A good majority of older persons cannot be hurried up. They need the sort of attention gently accorded children, and intensive medical facility and care, recreation and entertainment.

It is sad that, in over half a decade, post independent Nigeria is yet to enact a National Policy on the care of older persons as well as their welfare, neither is there social security scheme policy on old age. Ajomale ${ }^{7}$ agreed that bureaucratic bottle necks have hampered approval of drafts for implementation. The National Social Development Policy (1989) stipulated the main objective in respect of older persons and allocates responsibilities, yet the policies have proven to be ineffective. Again, sponsored by Nkiruka Onyejiocha (PDP, Abia) 'The bill for an Act has passed second reading in the House of Representatives, February 3, 2009, moving to create centres in the country that will cater for the needs of the senior citizens and for other matters connected therewith' old people's home is inferred.

Reasons for need the long term care for the elderly within the African region was reported by Aboderin ${ }^{1 "}$ Mama is not recovering well from the stroke. I know that there are ways of rubbing mama's affected areas on her body that can improve her condition, but I don't know how to do it and I don't have the money to take her to the hospital for them to do it there" "The care I give mama is not fully adequate. But I cannot devote all my time to her. I also have my life to live. If I don't look after my shop how can I make progress in life?".. "Mama needs more attention than I can give. I take care of my little children, myself and my husband... By the time I do all my household chores and I am tired, there is little or no strength in me to clean mama's room thoroughly" (Voices of carers, Nigeria). The misconception about the old people's homes could be seen from the word of Kenya Senators that, "We [should] delete the idea of establishing residential homes [for the elderly]. That is 'un-African' and it goes against our culture." 
Admitting a loved one into a long-term, skilled old people's facility, otherwise known as a old long term care home, is a difficult and extremely emotional decision for all involved especially within the African region. Here we will address common misconceptions and cultural perceptions that may or may not be true, but nevertheless influence our decisions and thought processes when a loved one may need the 24/7 care of old people's home within the African traditional set-ups. When faced with the daunting task of choosing the best facility for the needs of the patient and the family, the process becomes overwhelming, frustrating and even frightening. It's hard to know what to believe and what to dismiss. Some of the misconception about old people's homes is listed below

\section{Old people's homes are filled with people who are sick and dying}

This may be the most off-putting misconception. Today's centers are not where old people go to die; it's where the elderly go to find friends and activities and the security of knowing that they will never have to move again as they become less able to live independently.

\section{Dealing with guilt}

Our culture harbors the belief that when we have a loved one who needs the care of old people's home, the result is guilt and sadness for the family, and the end of any of life's joy for the patient. However, that does not have to be true. Doing your homework before a relative is admitted is the first step to making you both feel good about your decision. In developed countries where ailing seniors are happy to go to old peoples facility so they no longer feel guilty about the burden they feel they've been to the caregiver. Your loved one also may be relieved to receive the medical, rehabilitative and nursing care the healthcare professionals provide in the nursing home.

\section{Elderly in old people's homes smell bad}

It's true that incontinence is a fact of life in most Old people's homes, but today's cleaning methods and prompt attention to any sanitary issue is standard in most homes. If you encounter bad odors, the situation should be reported immediately. But in today's long term care world, lingering unpleasant odors are no longer an issue that cannot be resolved and the Care of the elderly in old people's home is very expensive

\section{Roles of social workers in old people's homes}

The National Association Social Worker ${ }^{8}$ the aging of the population presents social, economic, and political implications for families, the social work profession, and the global community. Social workers, other professionals, and the public increasingly recognize that advanced age is a time of continued growth and that older adults contribute significantly to their families, communities, and society. At the same time, many individuals face multiple bio-psychosocial challenges as they age: changes in physical and cognitive abilities; barriers to accessing comprehensive, affordable, and high-quality health and mental/behavioral health care; decreased economic security; lack of affordable, accessible housing; increased vulnerability to abuse and exploitation; and loss of meaningful social roles and opportunities to remain engaged in society. These challenges often affect entire families, who struggle to provide physical, emotional, financial, and practical support to their aging members.

Social workers who are employed in homes for the elderly perform a number of functions, including helping older adults adjust to life in their new residences, advocating for their clients' needs and rights, providing supportive counseling and making psychosocial assessments. These professionals, known as geriatric social workers, work in nursing homes, assisted living facilities and similar environments. Many homes might require that candidates hold a master's degree in social work as well as be licensed by the state (NASW, 2010).

\section{Psychosocial assessments}

When a resident is first admitted to an elderly home, a social worker will perform a psychosocial assessment to determine the level of care required and to assess whether specific services, such as counseling or psychiatric intervention, are needed. The purpose of a psychosocial assessment is to evaluate the person's biological, psychological and social needs, National Association of Social Workers,(2010). After an assessment is completed, the social worker discusses her findings with an interdisciplinary team, which usually consists of medical staff, occupational therapists, physical therapists and other professionals, to collaborate on formulating a treatment plan to address the resident's needs.

\section{Counseling and therapeutic services}

Social workers also help residents adjust to life in their new homes. Adjusting to life in a supportive care setting can be difficult and challenging for those used to living independently. A social worker provides individual and group counseling as needed to help her clients overcome potential emotional, psychological and social obstacles to adjustment. If the facility does not provide certain services, such as psychiatric care, the social worker will refer her client to the appropriate resources and professionals.

\section{Advocacy}

Social workers advocate for their clients to ensure that their needs are met and that their rights are protected. Social workers who work in elderly homes should stay up-to-date with legislative changes and policies that can affect their clients. They are responsible for ensuring that residents are protected from abuse and neglect, and should report any suspicion of abuse or neglect to facility administrators and to appropriate regulatory and law enforcement officials.

\section{Education}

In addition to educating her clients and their families about their rights and responsibilities, social workers also educate staff about the psychosocial needs of residents and provide training on multicultural and diversity issues. Social workers may conduct staff training seminars on these topics or discuss concerns as they arise with individual staff members. Social workers also provide consultation to the facility's administration to discuss relevant issues, such as the delivery of psychosocial care, as needed.

\section{Other tasks}

Social workers in elderly homes might be responsible for administrative tasks such as maintaining case files, writing case notes or reviewing treatment plans, participating in staff meetings and seminars and contributing to quality assurance meetings

\section{Acknowledgements}

Thank you for the anticipated help in publishing this work. 


\section{Conflict of interest}

We write to inform you that, there is no conflict of interest among the authors.

\section{References}

1. World Health Organization. World Report on Ageing \& Health, Geneva, Switzerland; 2015.

2. Oyinlola O. End of Care for the Elderly: Emerging Role of Medical Social Workers. Journal of Gerontological Geriatric Research. USA; 2016.

3. Aboderin I. Emerging Research focus on Long Term Care of Older Person in Sub-Saharan Africa. African Regional Conference on Gerontology and Geriatrics. Kenya; 2016.
4. Oyinlola O, Folaranmi O. Assessment of the effect of information access on emotional well-being of the elderly in Ibadan. Journal of Gerontological Geriatric Research. USA; 2016;5:298.

5. Okunola MI. Old Age Care. A Handbook for Nigerian Social Workers, Ibadan, Nigeria; 2002.

6. Okoye UO. Community-Based Care for Home Bound Elderly Persons in Nigeria; A policy Option. International Journal of Innovative Research in Science, Engineeringand Technology. 2013;2(12):7086-7089.

7. Ajomale O. Country report: Ageing in Nigeria Current state, social and economic implications. African Gerontological Society. 2007.

8. National Association Social Worker. Caregiving for Older Adults. Washington DC, USA; 2010 